\title{
ASSESSMENT OF CANAL WALLS AFTER BIOMECHANICAL PREPARATION OF ROOT CANALS INSTRUMENTED WITH PROTAPER UNIVERSAL ${ }^{\text {TM }}$ ROTARY SYSTEM
}

\author{
Carlos Menezes AGUIAR ${ }^{1}$, Daniela de Andrade MENDES ${ }^{2}$, Andréa Cruz CÂMARA ${ }^{3}$, Jose Antonio Poli de FIGUEIREDO ${ }^{4}$
}

\author{
1- DDS, MSc, PhD, Professor of Endodontics, Department of Prosthodontics and Oral and Facial Surgery, Dental School, Federal University of \\ Pernambuco, Recife, PE, Brazil. \\ 2- DDS, Master's degree student in Integrated Clinical Dentistry, Department of Prosthodontics and Oral and Facial Surgery, Dental School, Federal \\ University of Pernambuco, Recife, PE, Brazil. \\ 3- DDS, MSc, Doctorate student in Pharmaceutical Sciences, Department of Pharmaceutical Sciences, Federal University of Pernambuco, Recife, PE, \\ Brazil. \\ 4- DDS, MSc, PhD, Adjunct Professor of Endodontics and Coordinator of the Postgraduate Program in Dentistry, Pontifical Catholic University of \\ Rio Grande do Sul, Porto Alegre, Brazil . \\ Corresponding address: Prof. Dr. Carlos Menezes Aguiar - Rua Heitor Maia Filho, 52 - Apt. 201 - Madalena - Recife - PE - 50750-525 - Brasil - Phone: \\ +55-81-3467-6821- e-mail: cmaguiar.ufpe@yahoo.com.br
}

Received: September 17, 2008 - Modification: May 18, 2009 - Accepted: August 11, 2009

\begin{abstract}
O

bjective: The aim of this study was to examine the instrumented walls of root canals prepared with the ProTaper Universal ${ }^{\mathrm{TM}}$ rotary system. Material and Methods: Twenty mesiobuccal canals of human first mandibular molars were divided into 2 groups of 10 specimens each and embedded in a muffle system. The root canals were transversely sectioned $3 \mathrm{~mm}$ short of the apex before preparation and remounted in their molds. All root canals were prepared with ProTaper Universal ${ }^{\mathrm{TM}}$ rotary system or with Nitiflex ${ }^{\mathrm{TM}}$ files. The pre and postoperative images of the apical thirds viewed with a stereoscopic magnifier $(\times 45)$ were captured digitally for further analysis. Data were analyzed statistically by Fisher's exact test and Chi-square test at 5\% significance level. Results: The differences observed between the instrumented and the noninstrumented walls were not statistically significant $(\mathrm{p}<0.05)$. Conclusions: The Nitiflex ${ }^{\mathrm{TM}}$ files and the ProTaper Universal ${ }^{\mathrm{TM}}$ rotary system failed to instrument all the root canal walls.
\end{abstract}

Key words: Dental pulp cavity. Nickel-titanium. ProTaper Universal. Root canal preparation. Rotary instruments.

\section{INTRODUCTION}

The root canal preparation is one of the major components of root canal treatment and is directly related to subsequent disinfection and filling ${ }^{21,37}$. The goal of root canal preparation is to form a continuously tapered shape with the smallest diameter at the apical foramen and the largest at the orifice to allow effective irrigation and filling ${ }^{27}$, using techniques and instruments which have the greatest precision and the shortest working time ${ }^{13}$. Several types of endodontic instruments have been recommended but only a few seem to be capable of achieving these primary objectives of root canal preparation consistently ${ }^{5,26}$.

It has been recognized that NiTi rotary systems reduce the time required for biomechanical preparation and minimize the failures related to instrumentation ${ }^{7}$. Since their introduction, numerous NiTi rotary systems have been added to the arsenal of endodontics tools and sometimes the same manufacturer launches several instrument designs, trying to improve the performance of the file systems. The ProTaper UniversalTM $^{\text {TM }}$ rotary system is an example that can be mentioned. The ProTaper ${ }^{\mathrm{TM}}$ rotary instruments have a convex triangular cross-sectional design and a non-cutting safety tip. The basic series of ProTaper ${ }^{\mathrm{TM}}$ files comprise six instruments: three shaping and three finishing files. According to the manufacturer, the auxiliary shaping file SX should be used to produce more shape in the coronal portion of the root canal. The shaping file S1 should be used initially up to $4 \mathrm{~mm}$ short of the apex and the shaping files S1 and S2 throughout the working length to progressively enlarge the apical third. The finishing files (F1, F2 and F3) should be used to complete the apical third of the root canal ${ }^{1}$.

More recently, the ProTaper ${ }^{\mathrm{TM}}$ NiTi rotary system has been upgraded to the ProTaper Universal ${ }^{\mathrm{TM}}$ system, which includes shaping, finishing and retreatment instruments. It 
incorporates a shallow U-shaped groove at each of its convex triangular sides in cross section, supposedly to improve the flexibility of the larger instruments. The modified design has also been suggested to reduce the subjective feeling of the instrument being "pulled" into the canal or so-called screw-in effect ${ }^{2,18,30,31}$.

The aim of the present study was to evaluate the instrumented walls of root canals prepared with the ProTaper Universal $^{\mathrm{TM}}$ rotary system.

\section{MATERIAL AND METHODS}

Twenty mesiobuccal canals of human mandibular first molars obtained from the Tooth Bank of the Department of Prosthodontics and Oral and Facial Surgery of the Federal University of Pernambuco, Brazil were selected with the approval of the Research Ethics Committee of the University's Center of Health Sciences. The mesiobuccal roots had completely formed apices and severely curved root canals with curvature degrees ranging from $35^{\circ}$ to $60^{\circ}$ according to canal access angle (CAA) technique. The distance between the canal orifice and apex was connected by drawing a line. The angle formed by the intersection between this line and one drawn parallel to the long axis of the canal from the coronal part, is defined as the $\mathrm{CAA}^{11}$.

The coronal access was made, and the distal root was separated from the mesial root with a carborundum disk (KG Sorensen, Barueri, SP, Brazil). The distal root was returned to the Tooth Bank, and the mesial root was washed in running water for $2 \mathrm{~min}$ and left to dry at room temperature. A size 10 Senseus-Flexofile (Dentsply/ Maillefer, Ballaigues, Switzerland) was introduced into the mesiobuccal canal until its tip was visible at the apical foramen. The working length was calculated to be $1 \mathrm{~mm}$ less than the length obtained with this initial file.

The specimens were embedded in autopolymerized acrylic resin (Artigos Odontológicos Clássico Ltda., São Paulo, SP, Brazil) according to a previously described method $^{5}$. After polymerization, the acrylic blocks were removed from the molds and sectioned transversely $3 \mathrm{~mm}$ from the apex, for standardization purposes using a doublefaced diamond disk (KG Sorensen). The apical thirds were viewed with a stereoscopic magnifier $(\times 45)$ (Ramsor, São
Paulo, SP, Brazil) at the Biomaterials Clinical Research Unit (NPCB) of the Federal University of Pernambuco and the preoperative images were captured digitally. The specimens were remounted in their molds and the biomechanical preparation was performed.

\section{Biomechanical Preparation of the Root Canals}

The specimens were randomly divided into the following 2 groups with 10 root canals each. Random distribution of the groups considered the degree of canal curvature, allowing the average curvature, as well as the more severe cases to be evenly allocated to each group: Group 1: ProTaper Universal $^{\mathrm{TM}}$ rotary system (Dentsply/Maillefer). The canals were instrumented at a rotational speed of $300 \mathrm{rpm}$ (Driller Endo-Pro Torque, São Paulo, SP, Brazil) as follows: (1) SX file was used to one half of the WL; (2) S1 file was used up to $4 \mathrm{~mm}$ short of the apex; (3) S1 and S2 files were used to the full WL; and (4) F1, F2 and F3 files were used to the full WL. Group 2 (control): The canals were instrumented according to the crown-down technique with NitiFlex ${ }^{\mathrm{TM}}$ (Dentsply/Maillefer) hand files. The root canals were enlarged up to a size 30 master file.

Single-use instrumentation was performed. A freshly prepared 1\% sodium hypochlorite solution (Roval, Recife, PE, Brazil) was used in conjunction with ethylenediaminetetraacetic acid (EDTA - Biodinâmica, Ibiaporã, PR, Brazil) as a chelating agent for irrigating the root canals, as well as a $3-\mathrm{mL}$ syringe with a 30 -gauge needle (Injecta, Diadema, SP, Brazil). The irrigation was performed at the beginning of the instrumentation, after each instrument change, and at the end of the biomechanical preparation. A single operator prepared all root canals.

After instrumentation with files F1, F2 and F3 (group 1), and sizes 20, 25 and 30 (group 2), the specimens were removed from the acrylic resin moulds, and the apical third cross sections were viewed again with the stereoscopic magnifier $(\times 45)$ and the postoperative images were captured digitally.

The action of the instruments on the root canal walls (buccal, lingual, mesial, and distal) was analyzed according to a previously described method ${ }^{5}$. The data were recorded on individual record cards and the effectiveness of the instruments used was evaluated. The following scores were used: score 0 , absence of noninstrumented wall or walls;

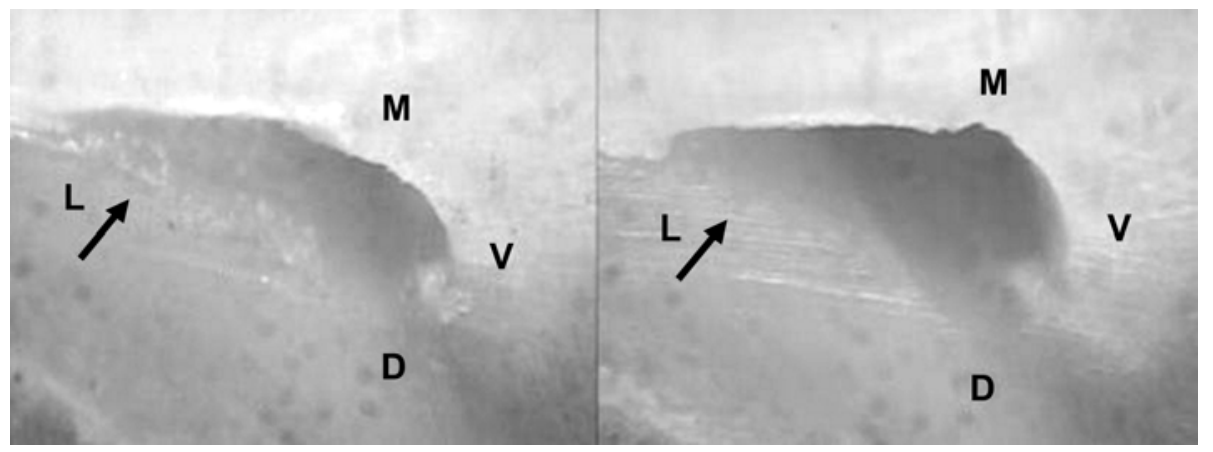

FIGURE 1- Preoperative image (left) and postoperative image (right) showing the absence of instrumentation at the lingual wall (arrow). M, mesial; D, distal; V, buccal; L, lingual (x45) 


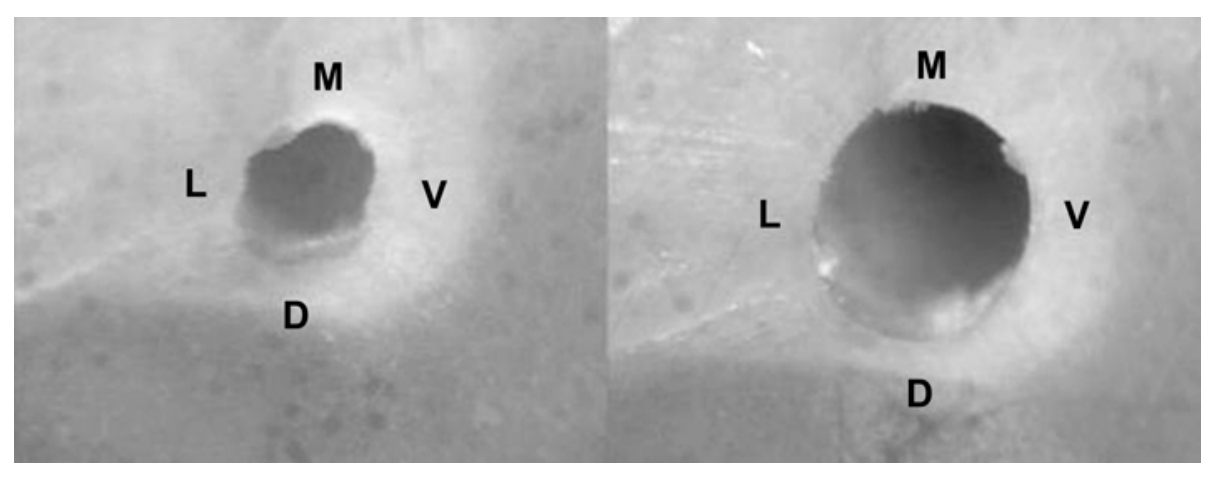

FIGURE 2- Preoperative image (left) and postoperative image (right) showing complete instrumentation of the walls. M, mesial; D, distal; V, buccal; L, lingual (x45)

TABLE 1- Frequency of instrumented walls according to the diameter of the instrument used

\begin{tabular}{|c|c|c|c|c|}
\hline \multirow[t]{3}{*}{ Wall/ Instrument } & \multicolumn{4}{|c|}{ Group } \\
\hline & \multicolumn{2}{|c|}{ Nitiflex ${ }^{T M}$ files } & \multicolumn{2}{|c|}{ ProTaper Universal ${ }^{\mathrm{TM}}$} \\
\hline & $\mathbf{n}$ & $\%$ & $\mathbf{n}$ & $\%$ \\
\hline \multicolumn{5}{|l|}{ Mesial } \\
\hline 20/F1 & 10 & 100.0 & 9 & 90.0 \\
\hline 25/F2 & 10 & 100.0 & 10 & 100.0 \\
\hline 30/F3 & 10 & 100.0 & 10 & 100.0 \\
\hline$P$ value & \multicolumn{2}{|c|}{$p=1.000$} & \multicolumn{2}{|c|}{$p=1.000$} \\
\hline \multicolumn{5}{|l|}{ Buccal } \\
\hline 20/F1 & 9 & 90.0 & 9 & 90.0 \\
\hline 25/F2 & 9 & 90.0 & 10 & 100.0 \\
\hline 30/F3 & 9 & 90.0 & 10 & 100.0 \\
\hline$P$ value & \multicolumn{2}{|c|}{$p=1.000$} & \multicolumn{2}{|c|}{$p=1.000$} \\
\hline \multicolumn{5}{|l|}{ Distal } \\
\hline 20/F1 & 8 & 80.0 & 8 & 80.0 \\
\hline $25 / F 2$ & 9 & 90.0 & 10 & 100.0 \\
\hline 30/F3 & 8 & 80.0 & 10 & 100.0 \\
\hline$P$ value & \multicolumn{2}{|c|}{$p=1.000$} & \multicolumn{2}{|c|}{$p=0.310$} \\
\hline \multicolumn{5}{|l|}{ Lingual } \\
\hline 20/F1 & 8 & 80.0 & 8 & 80.0 \\
\hline 25/F2 & 8 & 80.0 & 8 & 80.0 \\
\hline 30/F3 & 8 & 80.0 & 8 & 80.0 \\
\hline$P$ value & \multicolumn{2}{|c|}{$p=1.000$} & \multicolumn{2}{|c|}{$p=1.000$} \\
\hline \multicolumn{5}{|l|}{ Entire walls } \\
\hline 20/F1 & 35 & 87.5 & 34 & 85.0 \\
\hline 25/F2 & 36 & 90.0 & 38 & 95.0 \\
\hline 30/F3 & 35 & 87.5 & 38 & 95.0 \\
\hline$P$ value & \multicolumn{2}{|c|}{$p=1.000$} & \multicolumn{2}{|c|}{$p=0.215$} \\
\hline
\end{tabular}

$\mathrm{N}=$ number of walls 
score 1, presence of noninstrumented wall or walls (Figures 1 and 2). The results were tabulated and subjected to statistical analysis. The categorical data were summarized by means of absolute frequency and relative percentage and the numeric data by means of the usual descriptive statistics of location and dispersion. Interexaminer agreement regarding the instrumented walls was evaluated by Cohen's kappa test. Data referring to the instrumented walls were analyzed by Fisher's exact test and Chi-square test ${ }^{28}$. A level of significance of .05 was adopted for all the tests.

\section{RESULTS}

Table 1 shows the frequency of instrumented walls (buccal, lingual, mesial, and distal) according to the diameter (sizes 20, 25 and 30) of the instrument used (Nitiflex ${ }^{\mathrm{TM}}$ files and ProTaper Universal $\left.{ }^{\mathrm{TM}}\right)$. There was no statistically significant differences $(\mathrm{p}>0.05)$ between the instrumented and the noninstrumented walls. There was no evidence that any instrument was different from the others regarding its ability to instrument all root canal walls. A perfect interexaminer agreement was observed in groups 1 and 2 $(\mathrm{k}=1.000)$

\section{DISCUSSION}

Various brands of NiTi rotary systems have been introduced in the market. Most of them come with a regularly tapered shaft, whereas the ProTaper Universal ${ }^{\text {TM }}$ rotary system has a varying taper along the length of the instrument ${ }^{2,18,30,31}$. The use of rotary NiTi files for root canal preparation significantly reduced the time required to instrument canals with minimal deviation from the original canal path compared with hand instrumentation ${ }^{1,5}$.

Although all phases of root canal treatment are equally important, cleaning and shaping of the root canal system demand the greatest effort on the part of the operator ${ }^{27}$. It should be mentioned the difficulty in shaping flattened root canals because the instruments might not act efficiently on all canal walls. This was observed in the present study in agreement with the findings of previous studies ${ }^{3,5,8,9,20,22,24,35}$, in which complete instrumentation of the root canals was not achieved in any of the groups evaluated.

In the present study, the F2 and F3 instruments were the most effective for apical instrumentation. This is in accordance with Baratto-Filho, et al. ${ }^{3}$ (2009), who observed that the cleaning ability of the apical instruments of the ProTaperTM system (F1, F2, and F3) was directly proportional to their diameter. On the other hand, Calberson, et al. ${ }^{4}$ (2004) recommend that care should be taken to avoid excessive removal at the inner curve, leading to danger zones when using F2 and F3 instruments in curved canals. In addition, care should also be taken to avoid deformation of the F3 instrument.

Two methods have been used commonly used for evaluation of root canal preparation: extracted human teeth or simulated root canals with strictly defined root canal curvatures in terms of angle and radius. In the present study, natural human teeth were used following other authors ${ }^{1,2,5,10,12,15-17,22,23,29,31,32,34-36}$ because they simulate more faithfully the situations encountered in vivo. Acrylic resin is not an optimum material for testing rotary instruments because it does not manage to reproduce the microhardness of dentin ${ }^{18}$ and the anatomic variation (enlargements, oval root canals, etc) that are frequent in root canals and cannot be easily simulated ${ }^{6}$.

Comparison of the pre and postoperative images of the root canal diameter allowed fro evaluating one of the most important points of root canal preparation, that is, the prepared canal should completely include the original canal and no unprepared areas should remain. A number of methods for investigating the effectiveness of endodontic instruments during the instrumentation of root canals have been used ${ }^{9,11,13,20,23,25,32}$. In the present study, in the same way as in previous investigations ${ }^{2,5,14,17,32,37}$, the preoperative and postoperative images of the canal cross sections were viewed under a stereoscopic magnifier with $\times 45$ magnification for analysis of the instrumented walls ${ }^{5,32}$. This method allows a relatively easy and repeatable comparison of preinstrumentation and postinstrumentation canals in a way that it is possible to analyze the action of the instruments on the root canal walls (buccal, lingual, mesial, and distal) ${ }^{33}$.

The original ProTaper ${ }^{\mathrm{TM}}$ system rotary instrument is the one of the most popular endodontic NiTi systems currently on the market. Numerous studies have been carried out to evaluate the shaping capabilities of these instruments using canals of varying geometry in plastic blocks and extracted teeth ${ }^{31}$. Veltri, et al. ${ }^{33}$ (2004) compared the shaping abilities of ProTaper ${ }^{\mathrm{TM}}$ instruments and GT rotary instruments and observed that the two systems produced no aberrations and changes in the working length. Paqué, Musch and Hülsmann ${ }^{20}(2005)$ as well as Foschi, et al. ${ }^{8}$ (2004) related that the ProTaper ${ }^{\mathrm{TM}}$ system respected the original root canal curvature and were safe to use, but the cleanliness was not satisfactory.

More recently, the ProTaper ${ }^{\mathrm{TM}}$ NiTi rotary system has been upgraded to the ProTaper UniversalTM system. The manufacturer has modified the design and tip of some instruments. Ünal, et al. ${ }^{31}$ (2009) evaluated whether the changes of the ProTaper ${ }^{\mathrm{TM}}$ system contributed to the shaping ability of the instruments in terms of the morphology of curved canals. The authors observed that the modifications of the ProTaper ${ }^{\mathrm{TM}}$ instruments did not create any discrepancy in the shaping abilities of the instruments and others factors such as working time, instrument fracture, instrument deformation, and maintenance of working length. Williamson, Sandor and Justman ${ }^{36}$ (2009) compared the cleaning effectiveness under scanning electron microscopy using three different rotary NiTi systems (ProTaper Universal, ProFile GT and EndoSequence) and reported that all the rotary systems were equally effective in root canal debridement.

This study evaluated the instrumented walls of root canals prepared with the ProTaper Universal ${ }^{\mathrm{TM}}$ rotary 
system. The analysis of the root canal walls revealed that in the ProTaper Universal group, the F1 instrument was not able to prepare all of the root canal walls. When the F2 and F3 files were used, it was found that, except for the lingual wall, all other canal walls were instrumented. In the Nitiflex ${ }^{\mathrm{TM}}$ group, independent of the diameter of the instrument used only the mesial wall was fully prepared, and even increasing the diameter of the instrument, walls still remained without being instrumented. This apparent more effective action of ProTaper Universal ${ }^{\mathrm{TM}}$ system on the root canal walls compared the Nitiflex ${ }^{\mathrm{TM}}$ files could be explained by the fact that the ProTaper Universal ${ }^{\mathrm{TM}}$ instruments have a varying taper. Accordingly, a previous study $^{2}$ has demonstrated that ProTaper Universal ${ }^{\mathrm{TM}}$ has good capacity to shape root canals. However, though differences existed in the present study they were not statistically significant and both types of instruments produced similar results with minimal non-instrumented walls.

One of the great aspirations of endodontics is the emergence of an effective endodontic instrument that manages to maintain the original curvature of the root canals and at the same time works on all the walls. None of the instruments evaluated in this study was totally effective in performing the biomechanical preparation of the root canals, uninstrumented walls being observed.

\section{CONCLUSIONS}

Within the limitations of this present study, the Nitiflex ${ }^{\mathrm{TM}}$ files and the ProTaper Universal ${ }^{\mathrm{TM}}$ rotary system failed to instrument the apical third walls of the root canals, but demonstrated an acceptable capacity to shape root canals.

\section{REFERENCES}

1- Aguiar CM, Câmara AC. Radiological evaluation of the morphological changes of root canals shaped with ProTaper ${ }^{\mathrm{TM}}$ for hand use and the ProTaper ${ }^{\mathrm{TM}}$ and $\mathrm{RaCe}^{\mathrm{TM}}$ rotary instruments. Aust Endod J. 2008;34:115-

2- Aguiar CM, Mendes DA, Câmara AC, Figueiredo JAP. Evaluation of the centreing ability of the ProTaper Universal ${ }^{\mathrm{TM}}$ rotary system in curved roots in comparison to Nitiflex ${ }^{\mathrm{TM}}$ files. Aust Endod J. [serial on the internet] 2009 [cited 2009 Nov 4]. In press. Available from: http://dx.doi.org/ 10.1111/j.1747-4477.2009.00168.x

3- Barato-Filho F, Leonardi DP, Zielak JC, Vanni JR, Sayão-Maia SM, Sousa-Neto MD. Influence of ProTaper finishing files and sodium hypochlorite on cleaning and shaping of mandibular central incisors- a histological analysis. J Appl Oral Sci. 2009;17:229-33.

4- Calberson FL, Deroose CAJ, Hommez GM, De Moor RJ. Shaping ability of ProTaper nickel-titanium files in simulated resin root canals. Int Endod J. 2004;37:613-23.

5- Câmara AC, Aguiar CM, Figueiredo JAP. Assessment of the deviation after biomechanical preparation of the coronal, middle and apical thirds of root canals instrumented with three Hero Rotary Systems. J Endod. 2007;33:1460-3
6- Diemer F, Sinan A, Calas P. Penetration depth of warm vertical guttapercha pluggers: impact of apical preparation. J Endod. 2006;32:123-6.

7- Ferraz CC, Gomes NV, Gomes BP, Zaia AA, Teixeira FB, Souza-Filho FJ. Apical extrusion of debris and irrigants using two hand and three engine-driven instrumentation techniques. Int Endod J. 2001;34:354-8.

8- Foschi F, Nucci C, Montebugnoli L, Marchionni S, Breschi L, Malagnino VA, et al. SEM evaluation of canal wall dentine following use of Mtwo and ProTaper NiTi rotary instruments. Int Endod J. 2004;37:8329.

9- Grecca FS, Garcia RB, Bramante CM, Moraes IG, Bernardineli N. A quantitative analysis of rotary, ultrasonic and manual techniques to treat proximally flattened root canals. J Appl Oral Sci. 2007;15:89-93

10- Guelzow A, Stamm O, Martus P, Kielbassa AM. Comparative study of six rotary nickel-titanium systems and hand instrumentation for root canal preparation. Int Endod J. 2005;38:743-52.

11- Günday M, Sazak H, Garip Y. A Comparative study of three different root canal curvature measurement techniques and measuring the canal access angle in curved canals. J Endod. 2005;31:796-8.

12- Hülsmann M, Schade M, Schäfers F. A comparative study of root canal preparation with HERO 642 and Quantec SC rotary Ni-Ti instruments. Int Endod J. 2001;34:538-46.

13- Iqbal MK, Maggiore F, Suh B, Edwards KR, Kang J, Kim S, et al. Comparison of apical transportation in four Ni-Ti rotary instrumentation techniques. J Endod. 2003;29:587-91.

14- Iqbal MK, Firic S, Tulcan J, Karabucak B, Kim S. Comparison of apical transportation between ProFile ${ }^{\mathrm{TM}}$ and ProTaper ${ }^{\mathrm{TM}} \mathrm{NiTi}$ rotary instruments. Int Endod J. 2004;37:359-64.

15- Javaheri HH, Javaheri GH. A comparison of three Ni-Ti rotary instruments in apical transportation. J Endod. 2007;33:284-6.

16- Jeon IS, Spangberg LSW, Yoon TC, Kazemi RB, Kum KY. Smear layer production by 3 rotary reamers with different cutting blade designs in straight root canals: a scanning electron microscopic study. Oral Surg Oral Med Oral Pathol Oral Radiol Endod. 2003;96:601-7.

17- Kaptan F, Kayahan B, Haznedaroglu F, Tanalp J, Bayirli G. Comparative evaluation of the preparation efficacies of HERO shaper and Nitiflex root canal instrumentation in curved root canals. Oral Surg Oral Med Oral Pathol Oral Radiol Endod. 2005;100:636-42.

18- Kim HC, Cheung GSP, Lee CJ, Kim BM, Park JK, Kang SI. Comparison of forces generated during root canal shaping and residual stresses of three nickel-titanium rotary files by using a three-dimensional finite-element analysis. J Endod. 2008;34:743-7.

19- Kum K, Spängberg L, Cha BY, IL-Young J, Seung-Jang L, ChanYoung L. Shaping ability of three ProFile rotary instrumentation techniques in simulated resin root canals. J Endod. 2000;26:716-23.

20- Paqué F, Musch U, Hülsmann M. Comparison of root canal preparation using $\mathrm{RaCe}$ and ProTaper rotary NiTi instruments. Int Endod J. 2005;38:816.

21- Peters OA, Peters CI, Schonenberger K, Barbakow F. Protaper rotary root canal preparation: effects of canal anatomy on final shape analysed by micro CT. Int Endod J. 2003;36:86-92.

22- Prati C, Foschi F, Nucci C, Montebugnoli L, Marchionni S. Appearance of the root canal walls after preparation with NiTi rotary instruments: a comparative SEM investigation. Clin Oral Investig. 2004;8:102-10.

23- Santos MDB, Marceliano MF, Souza PR. Evaluation of apical deviation in root canals instrumented with K3 and ProTaper systems. J Appl Oral Sci. 2006;14:460-4 
24- Sasaki EW, Versiani MA, Perez DEC, Sousa-Neto MD, Silva-Sousa YTC, Silva RG. Ex vivo analysis of the debris remaining in flattened root canals of vital and nonvital teeth after biomechanical preparation with Ni-Ti rotary instruments. Braz Dent J. 2006;17:233-6.

25- Schäfer E, Vlassis M. Comparative investigation of two rotary nickeltitanium instruments: ProTaper versus RaCe. Part 1 . Shaping ability in simulated curved canals. Int Endod J. 2004;37:229-38.

26- Schäfer E, Erler M, Dammaschke T. Comparative study on the shaping ability and cleaning efficiency of rotary two instruments. Part 1. Shaping ability in simulated curved canals. Int Endod J. 2006;39:196-202.

27- Schilder H. Cleaning and shaping the root canal. Dent Clin North Am. 1974;18:269-96.

28- Shott S. Statistics for health professionals. 1st ed. Philadelphia: WB Saunders Company; 1990.

29- Tasdemir T, Aydemir H, Inan U, Ünal O. Canal preparation with Hero 642 rotary $\mathrm{Ni}-\mathrm{Ti}$ instruments compared with stainless steel hand $\mathrm{K}$-file assessed using computed tomography. Int Endod J. 2005;38:402-8.

30- Ünal GÇ, Kaya BU, Taç AG, Keçeci AD. A comparison of the efficacy of conventional and new retreatment instruments to remove gutta-percha in curved root canals: an ex vivo study. Int Endod J. 2009;42:344-50.

31- Ünal GÇ, Maden M, Savgat A, Onur Orhan E. Comparative investigation of 2 rotary nickel-titanium instruments: protaper universal versus protaper. Oral Surg Oral Med Oral Pathol Oral Radiol Endod. 2009; 107:886-92.

32- Uyanik MO, Cebreli ZC, Mocan BO, Dagli FT. Comparative evaluation of three Nickel-titanium instrumentation systems in human teeth using computed tomography. J Endod. 2006;32:668-71.

33- Veltri M, Mollo A, Pini PP, Ghelli LF, Balleri P. In vitro comparison of shaping abilities of ProTaper and GT rotary files. J Endod. 2004;30:1636.

34- Veltri M, Mollo A, Mantovani L, Pini PP, Balleri P, Grandini SA Comparative study of Endoflare-Hero Shaper and Mtwo NiTi instruments in the preparation of curved root canals. Int Endod J. 2005;38:610-6.

35- Weiger R, ElAyouti A, Löst C. Efficiency of hand and rotary instruments in shaping oval root canals. J Endod. 2002;28:580-3.

36- Williamson AE, Sandor AJ, Justman BC. A comparison of three nickel titanium rotary systems, EndoSequence, ProTaper Universal, and Profile GT, for canal-cleaning ability. J Endod. 2009;35:107-9.

37- Yang GB, Zhou XD, Zheng YL, Zhang H, Shu Y, Wu HK. Shaping ability of progressive versus constant taper instruments in curved root canals of extracted teeth. Int Endod J. 2007;40:707-14. 